\title{
Development of an online SPE-LC-MS-based assay using endogenous substrate for investigation of soluble epoxide hydrolase (sEH) inhibitors
}

\author{
Nils Helge Schebb • Marion Huby • \\ Christophe Morisseau • Sung Hee Hwang • \\ Bruce D. Hammock
}

Received: 15 January 2011 /Revised: 25 February 2011 / Accepted: 1 March 2011 /Published online: 9 April 2011

(C) The Author(s) 2011. This article is published with open access at Springerlink.com

\begin{abstract}
Soluble epoxide hydrolase (sEH) is a promising therapeutic target for the treatment of hypertension, pain, and inflammation-related diseases. In order to enable the development of sEH inhibitors (sEHIs), assays are needed for determination of their potency. Therefore, we developed a new method utilizing an epoxide of arachidonic acid (14 (15)-EpETrE) as substrate. Incubation samples were directly injected without purification into an online solid phase extraction (SPE) liquid chromatography electrospray ionization tandem mass spectrometry (LC-ESI-MS-MS) setup allowing a total run time of only $108 \mathrm{~s}$ for a full gradient separation. Analytes were extracted from the matrix within $30 \mathrm{~s}$ by turbulent flow chromatography. Subsequently, a full gradient separation was carried out on a 50X2.1 mm RP-18 column filled with $1.7 \mu \mathrm{m}$ core-shell particles. The analytes were detected with high sensitivity by ESI-MSMS in SRM mode. The substrate 14(15)-EpETrE eluted at a stable retention time of $96 \pm 1 \mathrm{~s}$ and its $\mathrm{sEH}$ hydrolysis product 14,15 -DiHETrE at $63 \pm 1 \mathrm{~s}$ with narrow peak width (full width at half maximum height: $1.5 \pm 0.1 \mathrm{~s}$ ). The analytical performance of the method was excellent, with a limit of detection of $2 \mathrm{fmol}$ on column, a linear range of over three orders of magnitude, and a negligible carry-over of $0.1 \%$ for 14,15 -DiHETrE. The enzyme assay was carried
\end{abstract}

Electronic supplementary material The online version of this article (doi:10.1007/s00216-011-4861-2) contains supplementary material, which is available to authorized users.

N. H. Schebb · M. Huby • C. Morisseau • S. H. Hwang •

B. D. Hammock $(\square)$

Department of Entomology and Cancer Research Center,

University of California,

One Shields Avenue,

Davis, CA 95616-8584, USA

e-mail: bdhammock@ucdavis.edu out in a 96-well plate format, and near perfect sigmoidal dose-response curves were obtained for 12 concentrations of each inhibitor in only $22 \mathrm{~min}$, enabling precise determination of $\mathrm{IC}_{50}$ values. In contrast with other approaches, this method enables quantitative evaluation of potent sEHIs with picomolar potencies because only 33 pmol L ${ }^{-1}$ sEH were used in the reaction vessel. This was demonstrated by ranking ten compounds by their activity; in the fluorescence method all yielded $\mathrm{IC}_{50} \leq$ $1 \mathrm{nmol} \mathrm{L}{ }^{-1}$. Comparison of 13 inhibitors with $\mathrm{IC}_{50}$ values $>1 \mathrm{nmol} \mathrm{L}^{-1}$ showed a good correlation with the fluorescence method (linear correlation coefficient 0.9, slope 0.95 , Spearman's rho 0.9). For individual compounds, however, up to eightfold differences in potencies between this and the fluorescence method were obtained. Therefore, enzyme assays using natural substrate, as described here, are indispensable for reliable determination of structure-activity relationships for $\mathrm{sEH}$ inhibition.

Keywords Soluble epoxide hydrolase (sEH) - Natural substrate enzyme assay Enzyme inhibitors turbulent-flow chromatography . Online-solid phase extraction $\cdot$ Liquid chromatography Electrospray mass spectrometry tandem mass spectrometry

\section{Introduction}

Soluble epoxide hydrolase $(\mathrm{sEH})$ inhibitors are a promising new class of potential drugs for treatment of a variety of diseases, for example inflammation, hypertension, and pain $[1,2]$. In order to develop new $\mathrm{sEH}$ inhibitors (sEHI) analytical techniques are needed to identify active compounds and quantitatively measure their potencies. Several 
in-vitro assays have been described utilizing surrogate substrates [3], for example cyano(6-methoxynaphthalen-2yl)methyl trans-[(3-phenyloxiran-2-yl)methyl] carbonate (CMNPC) $[4,5]$ or tritium-labeled trans-diphenylpropene oxide ( $t$-DPPO)[6]. However, because of the different recognition of dissimilar substrates by the enzyme, the measured potencies of sEHIs may differ among these methods. In order to obtain results predictive for in-vivo potency inhibition, assays utilizing the natural substrates are advantageous. Modern mass spectrometry (MS) enables parallel measurement of many natural enzyme substrates and products and is, thus, an excellent tool for measurement of enzyme activity and inhibition [7-11]. For the sEH, known natural substrates are epoxy fatty acids, which are metabolized to their corresponding fatty acid diols $[12,13]$. Among the epoxy fatty acids, arachidonic acid epoxides (EpETrEs) are best characterized. These have several biological effects, for example vasodilatory, antiinflammatory, and analgesic activity [1, 2, 14-17]. EpETrEs and their corresponding diols (DiHETrEs) can be sensitively detected by liquid chromatography electrospray (LC-ESI) MS [18, 19]. Consequentially, LC-ESIMS has already been used to monitor conversion of 14(15)EpETrE to 14,15-DiHETrE [3]. However, no LC-MSbased approach using natural a substrate has been described for the rapid determination of the potency of sEHI. For maximum sEH activity in cell-free in-vitro assays, volatile salts and stabilizing protein BSA are usually present in high concentrations [3]. Therefore, direct injection of these samples on conventional LC columns may lead to an irreversible absorption of proteins on the stationary phase, resulting in loss of chromatographic efficiency [20]. Moreover ESI-MS detection is significantly affected by this matrix, because of signal suppression or enhancement [21]. Matrix effects can still occur even when most of the proteins have been precipitated by organic solvent and removed by centrifugation [22]. Thus, a sample preparation step is needed before LC-ESI-MS analysis to ensure sensitive and reliable determination of small amounts of product formed in a difficult matrix. One fully automatable strategy is application of online solid-phase extraction (SPE), which enables direct injection of crude samples [23-25]. One of the most promising techniques for online SPE of protein-containing samples is the application of short, narrow columns filled with large particles (50$60 \mu \mathrm{m})$ [23-25]. At high flow rates, turbulent flow results, enhancing mass transfer between the mobile and stationary phases. This enables the separation of the small analyte molecules from the matrix, because of the larger diffusion coefficient of proteins [23-25]. Turbulent-flow chromatography (TFC) significantly reduces matrix effects by proteins in LC-ESI-MS quantification[26], and has found broad application in bioanalytical research, particularly for the analysis of drugs in biological samples [23-25, 27]. TFC was recently introduced as sample preparation for ESI-MS based enzyme inhibition assays by Vogel and coworkers [11]. In this work, we developed one of the fastest online SPE-LC-ESI-MS-MS methods described, by combining TFC with a separation on a sub- $2 \mu \mathrm{m}$ core-shell particlefilled RP-18 separation column. Together with a streamlined $\mathrm{sEH}$ inhibition assay in plate format, this method enables ranking of sEHIs with picomolar potencies by utilizing the endogenous substrate 14(15)EpETrE.

\section{Experimental}

Chemicals and biological materials

14(15)-Epoxy-eicosatrienoic acid (14(15)-EpETrE) and 14,15-dihydroxyeicosatrienoic acid (14,15-DiHETrE) (Fig. 1) were purchased from Cayman Chemicals (Ann Arbor, MI, USA). The internal standards, 10(11)-epoxydecaheptanoic acid (10(11)-EpHep) and 10,11-dihydroxydecaheptanoic acid (10,11-DiHHep) were synthesized as described elsewhere [18]. Urea derivatives previously synthesized in our laboratory were used as epoxide hydrolase inhibitors (sEHI) [28-32]. The chemical structures of four of the inhibitors are shown in Figs. 2 and 3. All other chemicals were obtained from Fischer Scientific (Pittsburgh, PA, USA) and were of the highest quality available. Baculovirus-expressed human soluble epoxide hydrolase $(\mathrm{sEH})$ was purified by affinity column chroma-

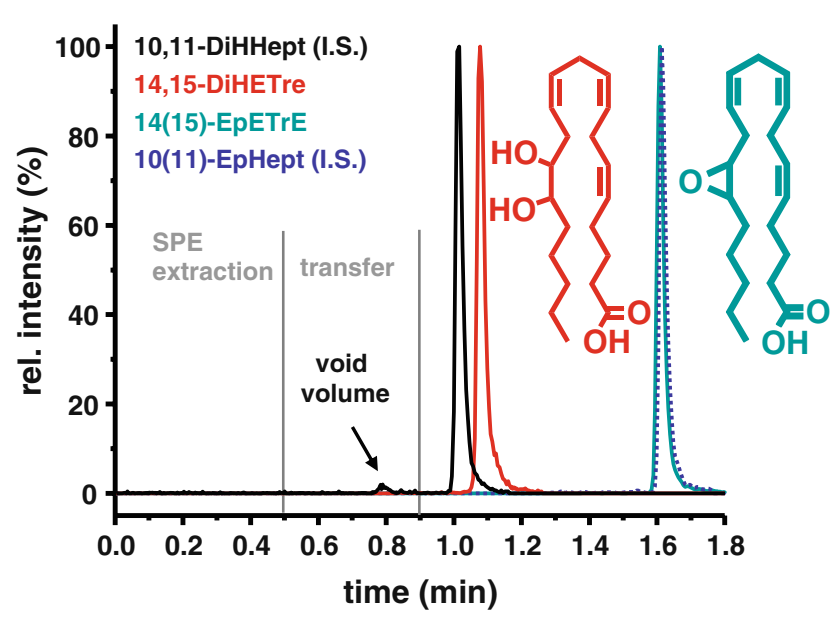

Fig. 1 SRM chromatogram obtained from the online SPE-LC-MS/ MS system. The signals of the product 14,15-DiHETrE (black line at $0.9 \mathrm{~min}$ ) and its I.S. 10,11-DiHHep (red line at $1.0 \mathrm{~min}$ ) and the coeluting substrate 14(15)-EpETrE (green) and its I.S. 10(11)-EpHHep (dashed blue line) at $1.6 \mathrm{~min}$ are shown after injection of $20 \mu \mathrm{L}$ standard solution containing $100 \mathrm{nmol} \mathrm{L}^{-1}$ of the compounds. The relative intensity ( $y$-axis) of each SRM transition is shown normalized to $100 \%$ intensity. The structure of the analytes is depicted beside of the peaks 


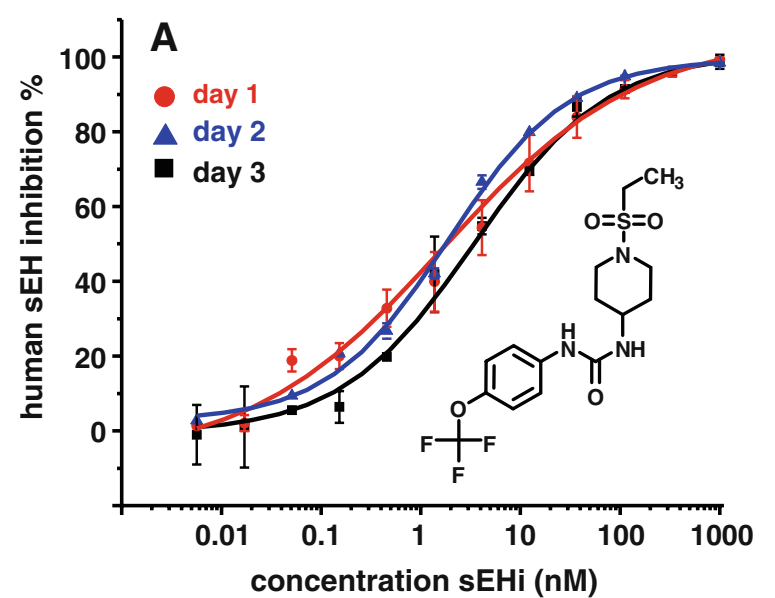

Fig. 2 Reproducibility and robustness of the method. Shown are the dose-response curves for sEHI 1. a Means of three independent determinations on three different days, using two different batches of

tography and its $100 \mu \mathrm{mol} \mathrm{L} \mathrm{L}^{-1}$ stock solutions in sodium phosphate buffer $\left(100 \mathrm{mmol} \mathrm{L}^{-1} \mathrm{pH} 7.4\right)$ was kept at $-80{ }^{\circ} \mathrm{C}$ until use [33].

Preparation of stock and standard solutions

Stock solutions of 14(15)-EpETrE, 14,15-DiHETrE, 10 (11)-EpHep, 10,11-DiHHep, and sEHIs were prepared in DMSO and kept at $4{ }^{\circ} \mathrm{C}$. All solutions for the assay were prepared on the day of analysis in $0.1 \mathrm{~mol} \mathrm{~L}^{-1}$ sodium phosphate buffer ( $\mathrm{pH}$ 7.4) containing $0.1 \mathrm{gL}^{-1}$ bovine serum albumin (BSA) and kept on ice until incubation. For the assay a $1 \mu \mathrm{mol} \mathrm{L} \mathrm{L}^{-1}$ enzyme solution of $\mathrm{sEH}$ was prepared from the stock solution in buffer; this was stable at

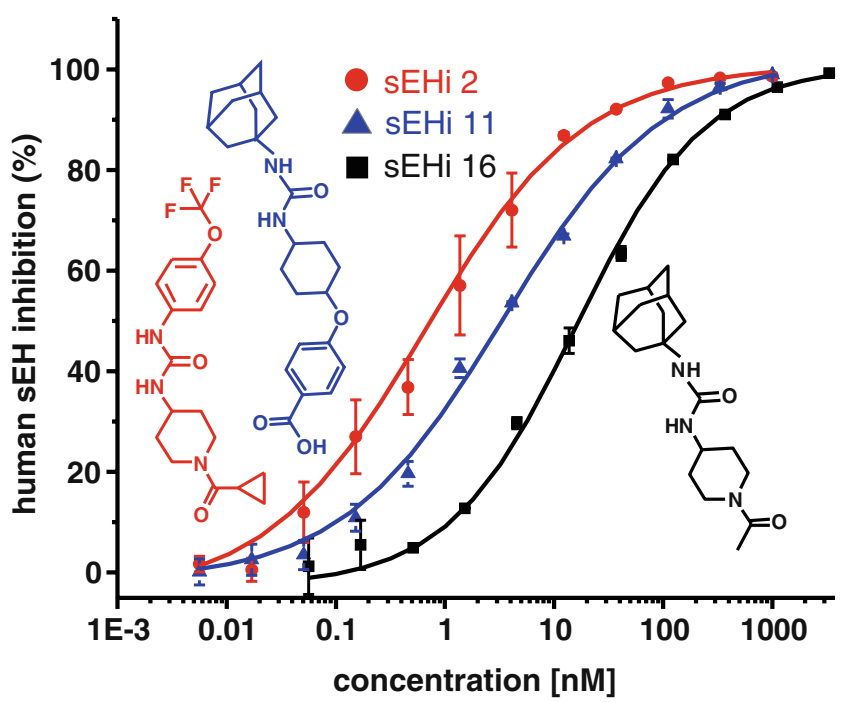

Fig. 3 Typical $\mathrm{IC}_{50}$ curves of the inhibition of human sEH by three different sEHI. Shown are the mean and deviation from duplicate determination. The structures of the sEHI are depicted beside the curves

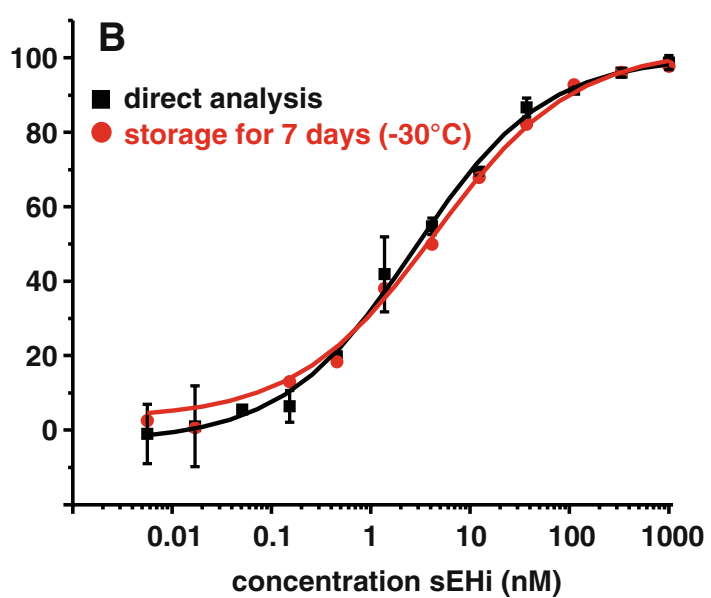

substrate and enzyme. b Comparison of a direct measurement after incubation and after 7 days storage at $-30{ }^{\circ} \mathrm{C}$. The structure of the inhibitor is shown in panel $A$

$4{ }^{\circ} \mathrm{C}$ for seven days. Before the incubation, this solution was further diluted with buffer to concentrations of 0.1 , 0.33 , and $1 \mathrm{nmol} \mathrm{L}^{-1}$. The substrate solution was freshly prepared by 1:100 dilution from the $1.5 \mathrm{mmol} \mathrm{L}^{-1}$ DMSO stock solution to $14,(15)$-EpETrE in buffer $\left(15 \mu \mathrm{mol} \mathrm{L}{ }^{-1}\right.$, $1 \%$ DMSO).

Inhibitor solutions of $3,10,30$, and $100 \mu \mathrm{mol} \mathrm{L}^{-1}$ were prepared by diluting stock solutions in buffer (final DMSO concentration: 1\%) within an hour before analysis and subsequently further diluted as described in the section "sEH inhibition assay". The reaction quench solution consisted of $20 \mu \mathrm{mol} \mathrm{L} \mathrm{L}^{-1}$ sEHI (1) and $200 \mathrm{nmol} \mathrm{L}^{-1}$ of the I.S. 10(11)-EpHep and 10,11DiHHep in ACN-water 50:50 $(v / v)$. For calibration a $0.5 \mathrm{mmol} \mathrm{L}^{-1}$ DMSO solution of 14(15)-EpETrE and 14,15 -EpETrE was sequentially diluted in a 96 -well plate in 50:50 $(v / v)$ ACN-water. Subsequently, the dilutions were mixed 1:1 with quench solution (final concentration $0.04 \mathrm{nmol} \mathrm{L}-1-2.5 \mu \mathrm{mol} \mathrm{L}{ }^{-1}$ ) and analyzed in the same way as samples.

Instrumental setup

Online SPE-LC was performed in back-flush mode utilizing a setup similar to that recently described [27]. In brief, the analytes (injection volume $20 \mu \mathrm{L}$ ) were extracted using a $(50 \times 0.5 \mathrm{~mm}, 50 \mu \mathrm{m}$ particle size) Cyclone RP-18 column (Thermo Fisher Scientific, Waltham, MA, USA) at a flow rate of $1500 \mu \mathrm{L} \mathrm{min}{ }^{-1} 0.1 \%$ acetic acid. After $30 \mathrm{~s}$ the sixport valve was switched, and the analytes were separated by a 78 -s binary gradient on a $(50 \times 2.1 \mathrm{~mm})$ Kinetex coreshell reversed-phase column (Phenomenex, Torrance, CA, USA) at a flow rate of $500 \mu \mathrm{L} \mathrm{min}{ }^{-1}$. Mass spectrometric detection was carried out in selected reaction monitoring mode (SRM) on an ABI 4000 TRAP tandem mass 
spectrometer after negative electrospray ionization (ESI). Details of the instruments used, the gradients applied, and the mass spectrometric conditions are presented in the Electronic Supplementary Material.

sEH inhibition assay

All sEH incubations were carried out in polypropylene 96well plates (Fisher Scientific) in a heated $\left(30{ }^{\circ} \mathrm{C}\right)$ shaker. For optimizing sEH concentration and incubation time, all wells were filled with $50 \mu \mathrm{L}$ buffer. Enzyme solutions of 1, 0.33 , and $0.1 \mathrm{nmol} \mathrm{L}^{-1}$ and buffer as control $(50 \mu \mathrm{L})$ were added to two rows for each concentration, by use of a twelve-channel pipette. Following pre-incubation for $5 \mathrm{~min}$ the conversion was started by adding $50 \mu \mathrm{L}$ substrate solution. After $0,5,10,20$, and $40 \mathrm{~min}, 150 \mu \mathrm{L}$ of quench solution was added to two rows at each time point. After incubation the plate was kept at $4{ }^{\circ} \mathrm{C}$ until online LC-MSMS analysis.

For the sEHI potency assay, wells in columns 2-12 were filled with $50 \mu \mathrm{L}$ buffer. Column 1 wells were filled with $75 \mu \mathrm{L}$ inhibitor solution (2-3 wells for each inhibitor). By use of an eight-channel pipette, $25 \mu \mathrm{L}$ from each cell in row 1 was transferred to the cells in row 2 and mixed three times with the pipette. This procedure was repeated for rows $2-12$, and, finally, $25 \mu \mathrm{L}$ from row 12 cells was removed and discarded. No inhibitor was added to wells G12 and H12, which served as positive and negative control, respectively. Thereafter, $50 \mu \mathrm{L}$ enzyme solution was added to all wells (except the negative control $\mathrm{H} 12$, to which $50 \mu \mathrm{L}$ additional buffer was added instead) and the plate was preincubated for $5 \mathrm{~min}$. After addition of $50 \mu \mathrm{L}$ substrate solution $\left(0.1 \mu \mathrm{mol} \mathrm{L}{ }^{-1}\right)$ to all wells with a twelve channel pipette, the plate was incubated for $30 \mathrm{~min}$. The reaction was stopped by adding $150 \mu \mathrm{L}$ quench solution to all wells and directly analyzed by online LC-MS-MS, or kept at $4{ }^{\circ} \mathrm{C}$ till analysis. The measured effect on $\mathrm{sEH}$ activity for each well was calculated as percentage of sEH inhibition based on the area ratio, $R$, of the product 14,15DiHETrE and its internal standard, 10,11-DiHHep by use of Eq.(1).

inhibition $(\%)=100-\frac{\left(R_{\text {sample }}-R_{\text {negative control }}\right) \cdot 100}{R_{\text {possitive control }}-R_{\text {negative control }}}$

The $\mathrm{IC}_{50}$ for the $\mathrm{sEHI}$ were calculated by fitting the dose-response curves of percentage inhibition values vs. log concentration with Origin 7.0 (OriginLab, MA, USA).

The potency of the SEHI was compared with the value from the commonly used fluorescence assay utilizing cyano (6-methoxynaphthalen-2-yl)methyl trans-[(3-phenyloxiran- 2-yl)methyl] carbonate (CMNPC) as substrate as described elsewhere [3, 4].

\section{Results and discussion}

\section{Online SPE-LC-ESI-MS-MS}

In the development of the new sEH inhibition assay a major emphasis was set on a rapid method of detection of the substrate 14(15)-EpETrE and its hydrolysis product 14,15DiHETrE (Fig. 1). The odd-chain fatty acid epoxide 10, (11)-EpHep and its corresponding diol, 10,11-DiHHep (Fig. 1) were used as internal standards. These were chosen because they have similar physicochemical properties to the arachidonate oxylipins, and they do not occur biologically in relevant amounts. The crude samples arising from enzymatic incubations were mixed with I.S. solution and directly analyzed by online-SPE-LC-MS-MS (Electronic Supplementary Material Fig. S1). The analytes were completely extracted by the online-SPE column and no analyte was detected in the flow through up to an elution volume of $6 \mathrm{~mL}$ (Electronic Supplementary Material Fig. S2). Salts and protein were directed to waste, and a minimum extraction time of $30 \mathrm{~s}$ corresponding to elution of 20 void volumes of the SPE column was found to be sufficient. Thereafter, the six-port valve was switched and the analytes were eluted in back-flush mode from the SPE column by the more hydrophobic flow $(57 \%$ ACN) delivered by pump 2 (Electronic Supplementary Material Fig. S1). The separation was carried out on a short $50 \times$ $2.1 \mathrm{~mm}, 1.7 \mu \mathrm{m}$ not fully porous "core-shell" particle filled, RP-18 column at a flow rate of $500 \mu \mathrm{L} \min ^{-1}$. Efficient mass transfer between stationary and mobile phases results from the short diffusion path in the shell type particles [34, $35]$. In addition to the advantages of sub-2- $\mu \mathrm{m}$ particle size, this column type leads to very high chromatographic resolution [36]. The mobile phase gradient was optimized to fully separate analytes from the void volume $(150 \mu \mathrm{L})$ of the analytical column where polar matrix compounds coextracted by SPE elute (Fig. 1). The dihydroxy fatty acid I. S. 10,11 DiHHep eluted first at a retention time of $59 \pm 1 \mathrm{~s}$ followed by 14,15 -DiHETrE at $63 \pm 1$ s. Despite the proximity of the retention times, these compounds were separated almost to the baseline, because of the narrow peak width, with full width at half maximum height (FWHM) of $1.4 \pm 0.1 \mathrm{~s}$ and $1.5 \pm 0.1 \mathrm{~s}$, respectively (Fig. 1). After elution of the diols, the gradient was increased to $95 \% \mathrm{ACN}$ over a period of $6 \mathrm{~s}$ to elute the epoxides. The 14,(15)-EpETrE and its I.S. 10,(11)-EpHept co-eluted at $96 \pm 1 \mathrm{~s}$ as narrow peaks (Fig. 1). Although it is not ideal that the substrate and its I.S. co-elute, quantification for the assay was carried out on the basis of product 
formation, and the product and its I.S. are ideally baseline separated. MS detection of the fatty acid derivatives was carried out after negative ESI in selected reaction monitoring mode (SRM), using the same transitions as previously described [18, 19].

A disadvantage inherent in the application of online SPE is the risk of carry over from the previous sample [25]. To investigate carry over, the highest concentration sample $\left(2.5 \mu \mathrm{mol} \mathrm{L}{ }^{-1}\right)$ was injected and the analyte area obtained was compared with that for a subsequent blank injection. We found carry-over was $0.1 \%$ for 14,15-DiHETrE and $0.4 \%$ for $14(15)$-EpETrE. Therefore it is expected there will be negligible interference from carry-over in the assay.

The method was calibrated using a series of standard solutions of 14,15-DiHETrE and 14(15)-EpETrE, which were treated in the same manner as incubation samples. The limit of detection (LOD, $S / N=3$ ) for 14,15-DiHETrE and 14(15)-EpETrE was $0.1 \mathrm{nmol} \mathrm{L}^{-1}$ (2 fmol on column) and method provided for both analytes a broad linear detection range over three orders of magnitude $\left(R^{2} \geq 0.999\right)$ from the limit of quantification (LOQ, $S / N=9$ ) up to $800 \mathrm{nmol} \mathrm{L}{ }^{-1}$. To investigate matrix effects on the quantification, we spiked the protein-containing reaction buffer with 10 $800 \mathrm{nmol} \mathrm{L}^{-1}$ of the analytes. These concentration ranges correspond to the product concentration at a conversion rate of $0.2-30 \%$ of the enzymatic assay (section "sEH inhibition assay"). As shown in Electronic Supplementary Material Fig. S3, recovery of the analytes was within $\pm 20 \%$ for all the concentrations tested, so direct injection of quenched incubation samples did not compromise analytical performance. because of the ultra-rapid online-SPE-LC-MS-MS (total analysis time $1.8 \mathrm{~min}$ ) more than 30 samples can be analyzed in one hour, rendering this approach ideal for enzyme inhibition assays with a large sample sets.

\section{sEH inhibition assay}

The enzyme inhibition assay was developed in a robust 96well-plate format for rapid investigation of sEHI libraries. In a final volume of $150 \mu \mathrm{L}$ the assay was carried out by mixing equal volumes $(50 \mu \mathrm{L})$ of inhibitor (buffer for controls), substrate, and enzyme solution followed by incubation. All pipetting steps were performed with a volume of at least $25 \mu \mathrm{L}$, enabling reproducible use of multichannel pipettes and making adaptation for use with fully-automated pipetting robots easily possible. The enzyme assay was carried in $0.1 \mathrm{~mol} \mathrm{~L}^{-1}$ sodium phosphate buffer ( $\mathrm{pH} 7.4$ ) containing $0.1 \mathrm{gL}^{-1}$ bovine serum albumin (BSA) at $30{ }^{\circ} \mathrm{C}$, as described previously [3]. The substrate concentration in the assay was set to the $K_{\mathrm{M}}$ value of $5 \mu \mathrm{mol} \mathrm{L}{ }^{-1}$ for the conversion of 14(15)-EpETrE by human sEH[37]. Incubation time and enzyme concentration were optimized to keep the enzyme concentration as low as possible to enable measurement of $\mathrm{IC}_{50}$ values for potent inhibitors. It was found that an enzyme concentration of only 33.3 pmol L ${ }^{-1}$ was sufficient. The conversion of 14 (15)-EpETrE was linear over the incubation time. Within $30 \mathrm{~min}, 298 \pm 18 \mathrm{nmol} \mathrm{L}^{-1}$ 14,15-DiHETrE was formed. This corresponds to substrate conversion of $5.9 \pm 0.4 \%$ and thus indicates that the initial velocity of the enzyme reaction was constant over the whole incubation time. Because of the high sensitivity of the online LC-ESI-MSMS method, low product concentrations can be reliably quantified (section "Online SPE-LC-ESI-MS-MS”). Because no significant non-enzymatic chemical hydrolysis of the substrate occurred $(0.13 \pm 0.06 \%)$, the approach enables quantitative measurement of $\mathrm{sEH}$ inhibition with a good signal-to-noise ratio based on product formation. However, the substrate concentration in the samples exceeds the dynamic range of the detection method, and thus could not be monitored simultaneously, although it would be technically feasible to do so. After the incubation, the reaction was stopped by adding an equal volume of quenching solution $(150 \mu \mathrm{L})$. The ACN content of this solution was adjusted to be as high as possible to denature the enzyme and increase the solubility of the low polar oxylipins. However, concentrations above $50 \% \mathrm{ACN}$ in water in the quenching solution caused precipitation of proteins and salts, making direct injection into the online SPE-LC-MSMS system impossible. When 50:50 (v/v) ACN-water was used as the quenching solution, it was also found that $\mathrm{sEH}$ was not fully inactivated by the organic solvent and the 14,15-DiHETrE concentration increased in the quenched samples over time. Therefore sEHI (1) was added to the quenching solvent at a high concentration of $20 \mu \mathrm{mol} \mathrm{L} \mathrm{L}^{-1}$ to fully inactivate the enzyme. With this optimized quenching solution incubation samples were stable over a storage time of at least 7 days at $-20{ }^{\circ} \mathrm{C}$ or $4{ }^{\circ} \mathrm{C}$ (Fig. 2).

Measurement of sEHI potency was carried out by investigating 14,15-DiHETrE formation in the presence of twelve concentrations of each inhibitor compared with control samples. In a generic scheme, $50 \mu \mathrm{L}$ of $3 \mu \mathrm{mol} \mathrm{L} \mathrm{L}^{-1}$ solutions of sEHI in buffer (1\% DMSO) were added to the wells of the first row of a 96-well plate and were sequentially diluted threefold per step. The resulting series of dilutions (final concentration in assay $6 \mathrm{pmol} \mathrm{L}^{-1}$

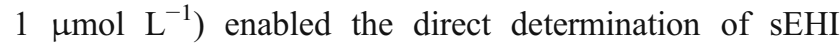
potency within a wide dynamic range. To ensure the accuracy of the measurements, at least three concentrations above and three concentrations below the $\mathrm{IC}_{50}$ should be investigated [38]. The dilution series therefore enabled the evaluation of $\mathrm{sEHI}$ with an $\mathrm{IC}_{50}$ range of $0.1 \mathrm{nmol} \mathrm{L}^{-1}$ to $100 \mathrm{nmol} \mathrm{L}^{-1}$, without any modification of this procedure. However, for investigation of sEHI of low potency (high $\mathrm{IC}_{50}$ value), the initial concentration of the inhibitor solution was increased to $3.3,10$, and $33.3 \mu \mathrm{mol} \mathrm{L}{ }^{-1}$. The 
Table 1 Determined $\mathrm{IC}_{50}$ values for inhibition of human $\mathrm{sEH}$ for a small library of 23 different urea derivatives. The results from the developed LC-MS assay are compared with those from the commonly used fluorescence (FD) assay

\begin{tabular}{|c|c|c|}
\hline $\begin{array}{l}\text { Inhibitor } \\
\text { no. }\end{array}$ & $\begin{array}{l}\mathrm{IC}_{50} \mathrm{FD} \text { assay } \\
\left(\mathrm{nmol} \mathrm{L}{ }^{-1}\right)\end{array}$ & $\begin{array}{l}\mathrm{IC}_{50} \mathrm{LC}-\mathrm{MS} \text { assay } \\
\left.(\mathrm{nmol} \mathrm{L})^{-1}\right)\end{array}$ \\
\hline 1 & $\leq 1$ & $2.4 \pm 0.6$ \\
\hline 2 & $\leq 1$ & $0.7 \pm 0.3$ \\
\hline 3 & $\leq 1$ & $5.4 \pm 0.9$ \\
\hline 4 & $\leq 1$ & $1.8 \pm 0.5$ \\
\hline 5 & $\leq 1$ & $4.9 \pm 1.3$ \\
\hline 6 & $\leq 1$ & $1.3 \pm 0.4$ \\
\hline 7 & $\leq 1$ & $1.3 \pm 0.3$ \\
\hline 8 & $\leq 1$ & $1.4 \pm 0.1$ \\
\hline 9 & $\leq 1$ & $5.0 \pm 0.1$ \\
\hline 10 & $\leq 1$ & $2.2 \pm 0.3$ \\
\hline 11 & 2 & $3.2 \pm 0.3$ \\
\hline 12 & 4 & $4.4 \pm 0.2$ \\
\hline 13 & 3 & $7.3 \pm 3.1$ \\
\hline 14 & 3 & $22.5 \pm 3.8$ \\
\hline 15 & 14 & $13.1 \pm 5.4$ \\
\hline 16 & 15 & $16 \pm 0.4$ \\
\hline 17 & 28 & $18.2 \pm 2.8$ \\
\hline 18 & 39 & $24 \pm 5$ \\
\hline 19 & 133 & $171 \pm 25$ \\
\hline 20 & 284 & $368 \pm 51$ \\
\hline 21 & 684 & $111 \pm 20$ \\
\hline 22 & 1011 & $567 \pm 81$ \\
\hline 23 & 1441 & $1323 \pm 26$ \\
\hline
\end{tabular}

resulting dose-response curves for sEHI inhibitors had a nearly theoretical sigmodial shape as shown in Fig. 3 for three inhibitors of significantly different potency. Together with the precise online SPE-LC-ESI-MS-MS measurement (intra sample variation $<5 \%$ ) this yielded consistent data sets for each inhibitor, which could be accurately fitted to obtain $\mathrm{IC}_{50}$ values (Fig. 3). The precision and reproducibility of the approach was demonstrated by repeated investigation of sEHI (1) (Fig. 2). The variation in the $\mathrm{IC}_{50}$ values of three replicates on a single plate (intra-plate variation) was consistently low $(15 \pm 6 \%, n=9)$. The intraday variation of three independent investigations on three different plates on a single day $(n=3)$ was also good $(9 \pm$ $6 \%$ ). The inter-day stability was calculated on the basis of the potencies determined on three different days using different batches of enzyme and substrate solution. The $\mathrm{IC}_{50}$ values for $\mathrm{sEHI}(1)$ were $2.1 \pm 0.1,1.9 \pm 0.1$, and $3.1 \pm$ $0.5 \mathrm{nmol} \mathrm{L}^{-1}$. The resulting intraday variation of only $25 \%$ emphasizes the robustness of the approach, rendering it ideal for the determination of sEHI potency with high precision.
Investigation of the potency of a library of sEHI

To demonstrate the performance of this approach a library of 13 competitive inhibitors, sEHI 11-23, was investigated for their potency, and the results obtained were compared with those from the commonly used fluorescence assay with CMNPC as surrogate substrate. As shown in Table 1 the $\mathrm{IC}_{50}$ of the investigated sEHI varied over three orders of magnitude from $2 \mathrm{nmol} \mathrm{L}^{-1}$ to $1300 \mathrm{nmol} \mathrm{L}^{-1}$ based on the fluorescence assay. It was found that $\mathrm{IC}_{50}$ values obtained with the LC-MS based assay using the natural substrate and the fluorescence assay correlated well, with a linear correlation coefficient between the methods of $R^{2}=0.9$ (Fig. 4). Because the slope of the linear correlation (potency fluorescence vs. natural substrate assay) was 0.95 overall the same potencies were obtained by both methods. Moreover, both methods sort the potency of tested sEHI in the same rank order, with a Spearman's rank correlation coefficient of 0.9. When comparing individual sEHI, the difference between both methods was generally lower than a factor of 2 (Table 1, Fig. 4). The two exceptions to the excellent correlation of $\mathrm{IC}_{50}$ values between the assays were sEHI (14) and sEHI (21). The $\mathrm{IC}_{50}$ value obtained by the new natural substrate assay was eightfold higher $\mathrm{IC}_{50}$ for sEHI (14) and a factor of 6 lower for sEHI (21) than those obtained from the fluorescence assay. However, these differences in $\mathrm{IC}_{50}$ values also occur between $\mathrm{sEH}$ assays utilizing different surrogate substrates. Tsai et al. reported recently reported strong variances between the potencies

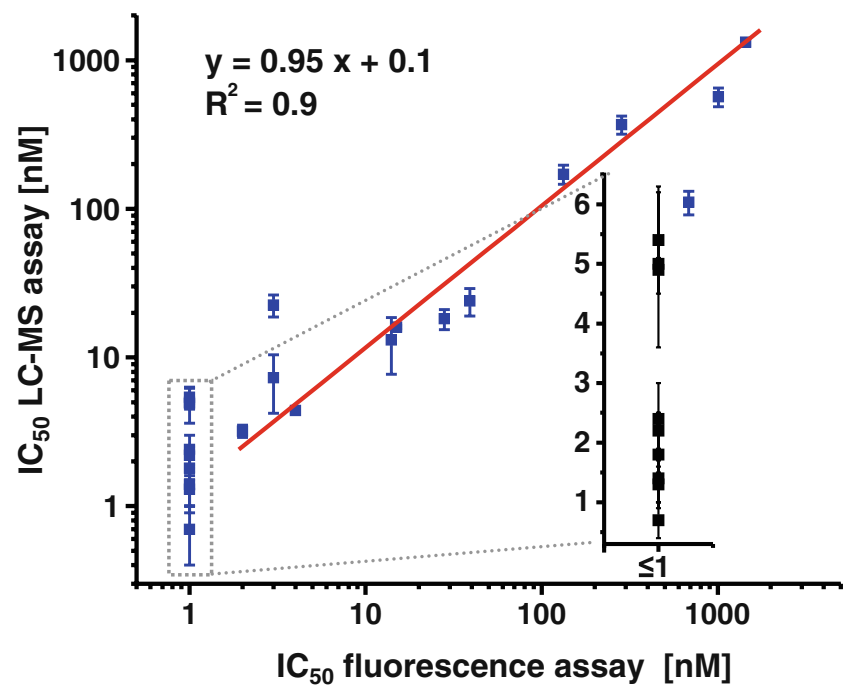

Fig. 4 Correlation of measured $\mathrm{IC}_{50}$ values between the newly developed LC-MS approach and the high-throughput fluorescence assay. The linear regression for inhibitors with $\mathrm{IC}_{50}>1 \mathrm{nmol} \mathrm{L}^{-1}$ in the florescence assay is shown in grey. The LC-MS assay results for potent inhibitors (fluorescence assay $\leq 1 \mathrm{nmol} \mathrm{L}^{-1}$ ) is shown enlarged in the inset, demonstrating that the fluorescence assay cannot distinguish among the most potent $\mathrm{sEHI}$ 
observed by the fluorescence assay using CMNPC as substrate and the radiometric assay utilizing t-DPPO as substrate [32]. For example the $\mathrm{IC}_{50}$ value for $\mathrm{sEH} 16$ (Fig. 3) was twentyfold higher for the radiometric assay compared with the fluorescence assay. Interestingly, the potency of this $\mathrm{sEH}$ determined with the natural substrate assay was in general agreement with those from the fluorescence assay (Table 1, Fig. 4). All tested sEHi were urea derivatives, for which it is known that they only act as competitive inhibitors [29-32]. Thus it is unlikely that an allosteric or irreversible inhibitory mode of action of the inhibitors causes the differences in the measured potencies. On the basis of on these findings, it is concluded that the $\mathrm{IC}_{50}$ value obtained for sEHI is not only affected by assay conditions, but is also dependent on the substrate used. The major mode of action of sEHI as a potential pharmaceutical is thought to be the stabilization of biologically active fatty acid epoxides, for example 14(15)-EpETrE [1, 39]. Thus, the values obtained from the natural substrate assay described in here should be more predictive of the efficacy of the sEHI in vivo.

The sEH concentration used in this assay is only 33 pmol L ${ }^{-1}$. This concentration is significantly lower than that used in other methods $\left(1 \mathrm{nmol} \mathrm{L}^{-1}\right)$ [3-6]. Given that the lowest $\mathrm{IC}_{50}$ value which can be reliable determined with an enzyme activity assay is equivalent to the enzyme concentration, this method is capable of quantitatively determining the potency of compounds with thirtyfold higher potency than all other methods up to an $\mathrm{IC}_{50}$ value as low as $0.03 \mathrm{nmol} \mathrm{L}^{-1}$. For the first time, the potency of the most powerful sEHI can be quantitatively investigated. This unique feature of the new method was demonstrated by ranking the competitive sEHI $(1-10)$ by their potency. All these inhibitors have potency $\leq 1 \mathrm{nmol} \mathrm{L} \mathrm{L}^{-1}$ in the fluorescence assay (Fig. 4; Table 1). However, none of these compounds had a potency significantly higher than $1 \mathrm{nmol} \mathrm{L}{ }^{-1}$ in the natural substrate assay. Moreover, many of the potent sEHI had $\mathrm{IC}_{50}$ values of $5 \mathrm{nmol} \mathrm{L}^{-1}$ and higher, as predicted by the fluorescence method. With potency of approximately $0.7 \pm 0.3 \mathrm{nmol} \mathrm{L} \mathrm{L}^{-1}$, sEHI (2) (Fig. 3) is the most potent of the inhibitors in the compound library investigated. This is comparable with the potencies of best sEHI inhibitors described so far [31] and no picomolar sEHIs were identified in this study. Nevertheless, the new approach described herein would enable characterization of picomolar $\mathrm{IC}_{50} \mathrm{~s}$, and thus might lead to the development of still more potent sEHI.

\section{Conclusion}

A new, LC-MS-based natural substrate approach for potency measurement of sEHI has been developed. In combination with a generic assay scheme in 96-well plate format, this new method enables reliable measurement of the potency of sEHI with high precision. By application of one of the fastest online SPE-LC-MS-MS systems described, just less than 22 min were needed for determination of the potency of a single compound. With an analysis time of $2.8 \mathrm{~h}$ per 96 -well plate, this assay cannot compete with spectral or fluorescence-based highthroughput assays. However, investigation of a small sEHI library indicates that, despite good overall correlation with data from surrogate assays, the determined potency for individual $\mathrm{sEHI}$ is substrate-dependent. The mode of action of sEHI in vivo is thought to be the stabilization of fatty acid epoxides. Thus, the utilization of an assay using the endogenous substrates is indispensable for reliable structure-activity relationship (SAR) analysis of sEHIs. With the method described herein, a fast highly automated technique is now available, which enables further development of highly potent sEHI.

Acknowledgements This study was supported by the National Institute of Environmental Health Sciences, R01 ES002710 and the NIEHS Superfund Research Program, P42 ES004699. The "Schormüller Foundation" of the German Chemical Society (GDCh), Division of Food Chemistry (Frankfurt, Germany), is gratefully acknowledged for financial support in the form of a scholarship for NHS. BDH is a George and Judy Marcus Senior Fellow of the American Asthma Foundation.

Open Access This article is distributed under the terms of the Creative Commons Attribution Noncommercial License which permits any noncommercial use, distribution, and reproduction in any medium, provided the original author(s) and source are credited.

\section{References}

1. Imig JD, Hammock BD (2009) Nat Rev Drug Discov 8:794-805

2. Inceoglu B, Jinks SL, Ulu A, Hegedus CM, Georgi K, Schmelzer KR, Wagner K, Jones PD, Morisseau C, Hammock BD (2008) Proc Natl Acad Sci USA 105:18901-18906

3. Morisseau C, Hammock BD (2007) Curr Protoc Toxicol 33:4.23.1-4.23.18

4. Jones PD, Wolf NM, Morisseau C, Whetstone P, Hock B, Hammock BD (2005) Anal Biochem 343:66-75

5. Wolf NM, Morisseau C, Jones PD, Hock B, Hammock BD (2006) Anal Biochem 355:71-80

6. Gill SS, Ota K, Hammock BD (1983) Anal Biochem 131:273282

7. Liesener A, Karst U (2005) Anal Bioanal Chem 382:1451-1464

8. Liesener A, Perchuc AM, Schoni R, Schebb NH, Wilmer M, Karst U (2007) Pure Appl Chem 79:2339-2349

9. Schebb NH, Falck D, Faber H, Hein EM, Karst U, Hayen H (2009) J Chromatogr A 1216:5249-5255

10. Schebb NH, Vielhaber T, Jousset A, Karst U (2009) J Chromatogr A 1216:4407-4415

11. Siemerink M, Schebb NH, Liesener A, Perchuc AM, Schoni R, Wilmer M, Hayen H, Karst U, Vogel M (2010) Rapid Commun Mass Spectrom 24:687-97

12. Morisseau C, Hammock BD (2005) Annu Rev Pharmacol Toxicol $45: 311-333$ 
13. Newman JW, Morisseau C, Hammock BD (2005) Prog Lipid Res 44:1-51

14. Inceoglu B, Jinks SL, Schmelzer KR, Waite T, Kim IH, Hammock BD (2006) Life Sci 79:2311-2319

15. Inceoglu B, Schmelzer KR, Morisseau C, Jinks SL, Hammock BD (2007) Prostaglandins Other Lipid Mediat 82:42-49

16. Roman RJ (2002) Physiol Rev 82:131-185

17. Spector AA, Fang X, Snyder GD, Weintraub NL (2004) Prog Lipid Res 43:55-90

18. Newman JW, Watanabe T, Hammock BD (2002) J Lipid Res 43:1563-1578

19. Yang J, Schmelzer K, Georgi K, Hammock BD (2009) Anal Chem 81:8085-8093

20. Souverain S, Rudaz S, Veuthey JL (2004) J Chromatogr B 801:141-156

21. Matuszewski BK (2006) J Chromatogr B 830:293-300

22. Polson C, Sarkar P, Incledon B, Raguvaran V, Grant R (2003) J Chromatogr B 785:263-275

23. Xu RN, Fan L, Rieser MJ, El-Shourbagy TA (2007) J Pharm Biomed Anal 44:342-355

24. Novakova L, Vlckova H (2009) Anal Chim Acta 656:8-35

25. Mullett WM (2007) J Biochem Biophys Methods 70:263-273

26. Liesener A, Karst U (2005) J Sep Sci 28:1658-1665

27. Schebb NH, Inceoglu B, Rose T, Wagner K, Hammock BD (2010) Anal Methods. doi:10.1039/c0ay00714e
28. Baumann A, Lohmann W, Rose T, Ahn KC, Hammock BD, Karst U, Schebb NH (2010) Drug Metab Dispos 38:2130-2138

29. Hwang SH, Morisseau C, Do Z, Hammock BD (2006) Bioorg Med Chem Lett 16:5773-5777

30. Hwang SH, Tsai HJ, Liu JY, Morisseau C, Hammock BD (2007) J Med Chem 50:3825-3840

31. Rose TE, Morisseau C, Liu JY, Inceoglu B, Jones PD, Sanborn JR, Hammock BD (2010) J Med Chem 53:7067-75

32. Tsai HJ, Hwang SH, Morisseau C, Yang J, Jones PD, Kasagami T, Kim IH, Hammock BD (2010) Eur J Pharm Sci 40:222-238

33. Beetham JK, Tian T, Hammock BD (1993) Arch Biochem Biophys 305:197-201

34. Gritti F, Guiochon G (2010) J Chromatogr A 1217:1604-1615

35. Olah E, Fekete S, Fekete J, Ganzler K (2010) J Chromatogr A 1217:3642-3653

36. Fekete S, Ganzler K, Fekete J (2011) J Pharm Biomed Anal 54:482-490

37. Zeldin DC, Wei S, Falck JR, Hammock BD, Snapper JR, Capdevila JH (1995) Arch Biochem Biophys 316:443-451

38. Assay Guidance Manual Version 5.0, 2008, Eli Lilly and Company and NIH Chemical Genomics Center. Available online at: http://www.ncgc.nih.gov/guidance/manual_toc.html (last accessed [24.02.2011])

39. Morisseau C, Inceoglu B, Schmelzer K, Tsai HJ, Jinks SL, Hegedus CM, Hammock BD (2010) J Lipid Res 51:3481-3490 